Review Article

\title{
THE EFFICACY OF COVID-19 VACCINE AND THE CHALLENGE IN IMPLEMENTING MASS VACCINATION IN INDONESIA
}

\section{KETUT TUNAS ${ }^{1}$, DEWA AYU AGUS SRI LAKSEMI², I. PUTU EKA WIDYADHARMA ${ }^{3}$, LUH PUTU RATNA SUNDARI ${ }^{4 *}$}

${ }^{1}$ Department of Health Information Management, Faculty of Health Sciences, Bali International University, Bali, Indonesia, ${ }^{2}$ Department of Parasitology, Faculty of Medicine, Udayana University, Denpasar, Bali, Indonesia, ${ }^{3}$ Department of Neurology, Faculty of Medicine, Udayana University, Denpasar, Bali, Indonesia, ${ }^{4}$ Department of Physiology, Faculty of Medicine, Udayana University, Bali, Indonesia

Email: luhputu_ratnafk@unud.ac.id

Received: 02 Mar 2021, Revised and Accepted: 25 May 2021

\section{ABSTRACT}

Novel coronavirus, severe acute respiratory syndrome coronavirus 2 (SARS-CoV-2), has caused more than 2,38 million deaths and more than 108 million cases confirmed in one year of the pandemic are massive upheavals in social life and economy in the international world. An effective vaccine is needed to prevent further morbidity and mortality. This research aims to identify the challenge in implementing mass vaccination in Indonesia which is related to the efficacy of the COVID-19 vaccine. We retrieve sources from relevant and published articles in Google Scholar, Pubmed, DOAJ and Science Direct of articles up to January 2021. The keywords used for gathering information were listed below. Vaccine efficacy is defined as the proportional reduction of a disease case in a group of vaccinated participants compared with unvaccinated participants. The study of vaccine efficacy is a cohort study that is an important vaccine trial method in the field. It is conducted randomly on a large scale by using a control-placebo. During the trials, the country which used the vaccine needs to maintain and observe the vaccine epidemiology. A trial roadmap is expected to identify the condition of the area epidemiologically. Vaccine efficacy is essential to be observed before implementing the vaccine in society. However, intensive socialization about the advantage of vaccines is mainly needed to prevent irrelevant information in social media about mass vaccination.

Keywords: Efficacy, Covid-19 vaccine, Mass vaccination, Challenge

(C) 2021 The Authors. Published by Innovare Academic Sciences Pvt Ltd. This is an open access article under the CC BY license (https://creativecommons.org/licenses/by/4.0/) DOI: https://dx.doi.org/10.22159/ijap.2021v13i4.41270. Journal homepage: https://innovareacademics.in/journals/index.php/ijap Speedy peer review was done as the subject of the manuscript was related with pandemic

\section{INTRODUCTION}

Novel coronavirus 2019 has been identified as the new infectious disease that appeared for the first time in December 2019 in China [1]. World Health Organization (WHO) states that this virus was a novel coronavirus 2019 (2019-nCoV) [2]. In February 2020, WHO announced that the name of the new disease is Coronavirus Disease (COVID-19) which was caused by Severe Acute Respiratory Syndrome Coronavirus-2 (SARS-CoV-2) [3]. As WHO has stated that COVID-19 is a global pandemic, [4] an effective vaccine to prevent and control the pandemic is needed and required [5].

In this pandemic condition, society needs to understand and define various methods and strategies such as intensive socialization and continuous campaign before vaccine utilization in preventing COVID-19. It is about the importance of mass vaccination to prevent and control this pandemic. Besides, it is significantly important to pay attention in the last six months about disease condition, model and characteristic of transmission, the severity of disease, area transmission, susceptible group and society discipline in implementing a strict health protocol through 3M (keep the distance, wash the hands and use the mask) to control the disease optimally and measurably.

Novel coronavirus, severe acute respiratory syndrome coronavirus 2 (SARS-CoV-2), has caused more than 2,38 million deaths and more than 108 million confirmed cases in a one-year pandemic [6], and there are massive upheavals in social life and economy in the international world. The SARS-CoV-2 virus was transmitted between individuals, primarily through droplets or other possible ways [7]. The virus can be transmitted from people to people with or without experiencing any symptoms [8]. During the recovery time, the patient can excrete virus' RNA for weeks $[9,10]$ and even can be longer in the immunosuppressed individuals [11].

Vaccine efficacy of COVID-19 is needed, at least, to prevent high severity caused by the infection of SARS-CoV-2. In order to gain this potential, well-maintained data collection is required to evaluate the cause of severe conditions and data on the disease severity. When the onset entered a hospital, it must be evaluated whether they need breathing apparatus or intensive handling from the current unit [12,
13]. An effective vaccine is demanded to prevent further morbidity and mortality. After one year of the global pandemic by WHO, many vaccines have been injected into people globally, including Indonesia. Others are still developing preclinical and clinical phases by still referring to procedures and testing [14].

\section{Definition and calculation of vaccine efficacy}

Along with vaccine development and testing, it is also necessary to have vaccine efficacy testing in society. Vaccine efficacy is defined as a proportional reduction of a disease case in a group of vaccinated participants compared with a group of unvaccinated participants (control-placebo) $[13,15]$. The definition of efficacy in this context shows the vaccine ability in cohort research activities. The calculation of vaccine efficacy uses the following formula:

$$
E_{v}=\left[\frac{\frac{x_{p}}{n_{p}}-\frac{x_{v}}{n_{v}}}{\frac{x_{p}}{n_{p}}}\right] \times 100
$$

and

$$
E_{v}=(1-R R) \times 100
$$

Information:

$\mathrm{E}_{\mathrm{v}}=$ vaccine efficacy $(\%)$

$\mathrm{x}_{\mathrm{p}}=$ the number of disease case in the unvaccinated group (placebo)

$\mathrm{X}_{\mathrm{V}}=$ the number of disease case in the vaccinated group

$\mathrm{n}_{\mathrm{p}}=$ the number of a participant in unvaccinated group (placebo)

$\mathrm{n}_{\mathrm{v}}=$ the number of a participant in the vaccinated group

$\mathrm{RR}=$ relative risk

Example

Phase 4 of the vaccine trial, randomized placebo-control double-blind, was conducted using random allocation (1:1), involving 2000 participants. 1000 participants were allocated as a vaccinated group, 
and 1000 participants received a placebo. After $28 \mathrm{~d}$, it has been identified that disease cases have occurred in 10 participants of the vaccinated group and 80 participants of the unvaccinated group. Applying the formula above shows that the percentage of disease cases in the vaccinated group is 0,01 or $1 \%$, and the percentage of the placebo group is 0,08 or $8 \%$. It means that vaccine efficacy is $87,5 \%$.

\section{Method in vaccine efficacy studies}

This research is expected to be strictly based on the scientific method, regardless of global economic and political interests, so that the further implemented vaccine in each country has sufficiently high efficacy in protecting its society from infection. Some countries might have set a high standard for the implemented vaccine in terms of efficacy and safety. However, globally, the main purpose of vaccine development is to obtain direct evidence of vaccine efficacy in protecting humans from SARS-CoV-2 or COVID-19 infection [16].

Efficacy studies must be pursued optimally to meet the efficacy targets and consider several variables, such as local transmission rate, participant's characteristic, the severity of COVID-19, variation of mortality rated based on age, gender, ethnic and others [17]. Several efforts have been made to fulfill all steps in vaccine development until vaccine implementation in the field [18]. Vaccine efficacy studies is a cohort study using an essential method in a vaccine trial in the field. It is conducted randomly on a large scale by using control-placebo, and this is the crucial part to be used as a basis for making decisions and regulatory policies about the certainty of the safety and efficacy of the vaccine candidates [19].

COVID-19 vaccine development has occurred, where some vaccine candidates are in phase 3 in the clinical trial stage [20]. The report of large-scale randomized field vaccine trials has been stated by Baden $e t$ al.,[21] Phase 3 trial is conducted in randomize disguised, controlplacebo in 99 research centers involving 30,402 volunteers in the United States of America. A person with a high risk of contrasting SARS-CoV-2 or the complications is allocated randomly with a ratio of 1:1 to get an intramuscular injection (IM) mRNA-1273 (100 $\mu \mathrm{g})$ expect placebo [21]. The trial concluded that the COVID-19 vaccine mRNA1273 has $94,1 \%$ efficacy in preventing COVID-19, including severe disease. The steps of a vaccine trial in each area are not exactly the same, which depends on the fund availability, decision-maker commitment and policyholder, volunteer availability and other supporting factors. However, at least, the evidence is based on the testing phase, and it can be justified so that once the vaccine is implemented in society, it is truly safe and provides optimal protection against exposure to COVID-19. Apart from Baden et al., Logunov et al., 2020 also has published the results of the efficacy and safety test of the Gam-COVID-Vac vaccine [22]. Phase 3 trial was held in 25 hospitals and polyclinic in Moscow (Russia) with a randomized, double-blind and placebo-controlled method. This trial involved $18 \mathrm{y}$ old participant and went through PCR SARS-CoV-2 PCR negative as well as IgG and IgM. The examination showed no infectious disease $14 \mathrm{~d}$ before the trial and did not have another vaccination $30 \mathrm{~d}$ before the trial. Participants were allocated randomly in a 3:1 ratio to receive a vaccine or placebo stratified by age group. The vaccine was administered by $0,5 \mathrm{ml} /$ dose IM in the regimen prime-boost, with intervals of $21 \mathrm{~d}$ between the first and second doses. From that trial result, it is concluded that phase 3 in the vaccine trial, Gam-COVID-Vac has $91,6 \%$ efficacy in resisting COVID-19 and has great tolerance on a larger scale.

Both Baden et al. and Logunov et al., in phase 3 vaccine trial have a similarity in process and methods, where the methodology of the trial is carried out under scientific principles with a cohort research design.

In Indonesia, a clinical trial is carried out by using the Sinovac vaccine. The sinovac vaccine, which has $65,3 \%$ of efficacy, is declared safe. Although it has side effects, they are mild and reversible. The concern related to antibody-dependent enhancement (ADE), as many mentioned in social media and became society's fear, did not occur in the Sinovac clinical trial in Indonesia or Turkey and Brazil [23]. 65,3\% of efficacy in a clinical trial means a reduction for $65,3 \%$ of disease cases in the vaccinated group compared to the unvaccinated group (placebo), and it was obtained in a controlled clinical trial. For example, clinical trial in Bandung, 800 subjects received the vaccine, and 800 subjects received a placebo (empty vaccine) among 1,600 participants. If in the vaccinated group, there are 26 infected subjects $(3,25 \%)$, while in the placebo are 75 subjects who are infected to COVID-19 $(9,4 \%)$, so the vaccine efficacy is $0,094-0,0325) / 0,094 \times 100 \%$ and the result is $65,3 \%$ [24]. It means that the ratio between vaccinated and unvaccinated groups become the defining factor. This efficacy will be affected by the test subject's characteristics. If the test subject is a high-risk group, so the probability of the placebo group will have more infected subjects, the calculation of efficacy will increase. If the test subject is a low-risk group and more subjects stay at home and even apply the health protocol strictly, there may be fewer infected subjects in the placebo group. It has caused the comparison of infection cases between placebo and vaccinated groups, resulting in a lower vaccine efficacy rate.

The efficacy result of the Sinovac vaccine was 65.3 percent, which might cause disappointment to some people, but this will be the first step where the agreement of minimum vaccine percentage from FDA, WHO and EMA is 50\%. It defines that decreasing the infection case by 50 percent epidemiologically is meaningful and has saved many people's lives.

\section{The role of policyholder in implementing mass vaccination}

Many vaccine candidates have entered the testing phase in several countries until phase 3 , and some have even implemented it. (WHO, 2020d) [20]. It shows that no vaccine may be excellent because of technology, but it depends on the epidemiological context in each implementation area [13].

Unlike the two developed countries mentioned above, the country does not produce the vaccine independently in implementing a vaccine in one's country. Cooperation between countries is needed. In this condition, vaccine safety and efficacy have been done by vaccine producer countries. A user country also can conduct a vaccine efficacy trial, although on a limited basis. After that, the vaccine producer country conducts the trial. The user country keeps observing the vaccine epidemiology. The trial roadmap is expected to recognize the condition of the area epidemiologically during the trial.

\section{Challenge in implementing mass COVID-19 vaccination in Indonesia}

Other than safety and vaccine efficacy which is the attention before implementing mass vaccination, there are several principles to be fundamentally understood by decision-makers or policyholders in Indonesia. Some challenges need to be noticed in implementing mass COVID-19 vaccination in Indonesia, such as determining the priority scale of groups to be vaccinated in the first place, whether it is based on susceptibility, age group, gender, profession, mobility or other categories. This priority scale of groups refers to WHO and the Department of Health instructions as the authorized agency to determine the category. After that, there is the determination of the stages of vaccination because the vaccination was intended for various age groups or certain professional groups, such as health workers and non-health workers (table 1) [25]. After that, the determination of a vaccine was done twice. These steps must be decided for the mass vaccination to be done properly and correctly.

Table 1: The stages of Covid-19 vaccination in Indonesia

\begin{tabular}{llll}
\hline Period I: Jan-April 2021 & & Period II: April 2021-Mar 2022 & \\
\hline $\mathbf{1}^{\text {st }}$ Phase & 2 $^{\text {nd }}$ Phase & $\mathbf{3}^{\text {rd }}$ Phase & 4 $^{\text {th }}$ Phase \\
\hline Health Workers & Public Servant & Vulnerable People & Other People \\
Health Workers in 34 Province & 17.4 Million & High-risk people of transmission & Based on Cluster depend on vaccine availability \\
1.3 Million & Elderly 21.5 Million & 63.9 Million & 77.4 Million \\
\hline
\end{tabular}


After the Indonesian government has decided on a sufficient amount of vaccine for the first phase, they consider the challenge of whether the vaccine distribution to arrive on time. It is because of the large area of Indonesia and the storage process for vaccines that requires special handling (cold chain) to maintain the quality of the vaccines. The next challenge is about the implementation. Indonesia had implemented vaccination for health workers. Follow-up events after immunization (KIPI) had been anticipated by all vaccination centers with observation post-immunization and offered the contact to be called for the post-immunization effect.

It is important to be understood, as there is no certainty about free vaccine or standalone vaccine (paid). According to the plan, this information is crucially needed by society to implement mass COVID-19 vaccination in the national vaccination program.

\section{CONCLUSION}

COVID-19 vaccine efficacy study is essential to obtain the safe vaccine and to give optimal protection from COVID-19. It is also important to hold intensive, continuous and massive socialization and campaign in order for society to be understood about the main purpose of vaccine implementation. The large area of Indonesia must be considered and noticed for the implementer of vaccination in the field, especially in logistic storage related to temperature, security of distribution track, the proportion of area requirements, the number of vaccine officers and other supporting facilities.

\section{FUNDING}

Nil

\section{AUTHORS CONTRIBUTIONS}

All authors contributed equally.

\section{CONFLICT OF INTERESTS}

There is no conflict of interest.

\section{REFERENCES}

1. Singh M, Nagpal M, Singh V, Sharma A, Dhingra GA, Maman P, et al. Covid-19: epidemiology, pathogenicity and global updates. Int J Appl Pharm 2020;12:16-28.

2. Wang E, Brar K. COVID-19 in children: an epidemiology study from china. J Allergy Clin Immunol Pract 2020;8:2118-20.

3. World Health Oranization. Naming the coronavirus disease (COVID-19) and the virus that causes it; 2020. Available from: https://www.who.int/emergencies/diseases/novelcoronavirus-2019/technical-guidance/naming-thecoronavirus-disease-(covid-2019)-and-the-virus-that-causesit. [Last accessed on 05 May 2021]

4. World Health Organization. WHO Director-General's opening remarks at the media briefing on COVID-19-11 March 2020 2020. Available from: https://www.who.int/directorgeneral/speeches/detail/who-director-general-s-openingremarks-at-the-media-briefing-on-covid-19---11-march-2020. [Last accessed on 05 May 2021]

5. Yamey G, Schaferhoff M, Hatchett R, Pate M, Zhao F, McDade KK. Ensuring global access to COVID-19 vaccines. Lancet 2020;395:1405-6.

6. Briefing WM. WHO Director-general's opening remarks at the media briefing on COVID-19. World Heal Organ; 2020. Available from: https://www.who.int/directorgeneral/speeches/detail/who-director-general-s-openingremarks-at-the-media-briefing-on-covid-19-12-march-2021

7. Khan S, Liu J, Xue M. Transmission of SARS-CoV-2, required developments in research and associated public health concerns. Frontiers Med 2020;7:310.

8. Oran DP, Topol EJ. Prevalence of asymptomatic SARS-CoV-2 infection: a narrative review. Annals Internal Med 2020;173:362-7.

9. Zheng S, Fan J, Yu F, Feng B, Lou B, Zou Q, et al. Viral load dynamics and disease severity in patients infected with SARS-CoV-2 in zhejiang province, China, January-March 2020: Retrospective cohort study. BMJ 2020;369. http://dx.doi.org/10.1136
10. To KKW, Tsang OTY, Leung WS, Tam AR, Wu TC, Lung DC, et al. Temporal profiles of viral load in posterior oropharyngeal saliva samples and serum antibody responses during infection by SARS-CoV-2:an observational cohort study. Lancet Infect Dis 2020;20:565-74.

11. Zhu L, Gong N, Liu B, Lu X, Chen D, Chen S, et al. Coronavirus disease 2019 pneumonia in immunosuppressed renal transplant recipients: a summary of 10 confirmed cases in wuhan, China. Eur Urol 2020;77:748-54.

12. Loeliger E, Chaudhari A. Article: COVID-19 efficacy endpoints in interventional trials: what constitutes an incident clinical disease case and what triggers diagnostic work-Up V2.0 - Epidemic Preparedness Innovations. Global Health Network; 2020. Available from: https://epi.tghn.org/articles/covid-19-efficacy-endpointsinterventional-trials-v20/. [Last accessed on 05 May 2021]

13. Hodgson SH, Mansatta K, Mallett G, Harris V, Emary KRW, Pollard AJ. What defines an efficacious COVID-19 vaccine? A review of the challenges assessing the clinical efficacy of vaccines against SARS-CoV-2. Lancet Infectious Diseases 2021;21:e26-35.

14. World Health Organization. Draft landscape and tracker of COVID19 candidate vaccines; 2020. Available from: https://www.who.int/publications/m/item/draft-landscape-ofcovid-19-candidate-vaccines. [Last accessed on 05 May 2021]

15. Weinberg GA, Szilagyi PG. Vaccine epidemiology: Efficacy, effectiveness, and the translational research roadmap. J Infectious Diseases 2010;201:1607-10.

16. U. S. Department of Health and Human Services. Development and Licensure of Vaccines to Prevent COVID-19 Guidance for Industry; 2020. Available from: https://www.fda.gov/regulatory. [Last accessed on 05 May 2021]

17. Docherty AB, Harrison EM, Green CA, Hardwick HE, Pius R, Norman L, et al. Features of 20133 UK patients in hospital with covid-19 using the ISARIC WHO Clinical Characterisation Protocol: Prospective observational cohort study. Br Med J; 2020. Available from: https://isaric4c.net. [Last accessed on 05 May 2021]

18. Lurie N, Saville M, Hatchett R, Halton J. Developing covid-19 vaccines at pandemic speed. $N$ Engl J Med 2020;382:1969-73.

19. Dean NE, Gsell PS, Brookmeyer R, De Gruttola V, Donnelly CA, Halloran ME, et al. Design of vaccine efficacy trials during public health emergencies. Sci Transl Med; 2019. Available from: https://pubmed.ncbi.nlm.nih.gov/31270270/. [Last accessed on 05 May 2021]

20. World Health Organization. Draft landscape and tracker of COVID-19 candidate vaccines; 2021. Available from: https://www.who.int/publications/m/item/draft-landscapeof-covid-19-candidate-vaccines. [Last accessed on 05 May 2021]

21. Baden LR, El Sahly HM, Essink B, Kotloff K, Frey S, Novak R, et al. Efficacy and Safety of the mRNA-1273 SARS-CoV-2 vaccine. N Engl J Med 2021;384:403-16.

22. Logunov DY, Dolzhikova IV, Shcheblyakov DV, Tukhvatulin AI, Zubkova OV, Dzharullaeva AS, et al. Safety and efficacy of an rAd26 and rAd5 vector-based heterologous prime-boost COVID-19 vaccine: an interim analysis of a randomised controlled phase 3 trial in Russia. Lancet 2021;397:671-81.

23. Ophinni Y, Hasibuan AS, Widhani A, Matia S, Koesnoe S, Yunihastuti E, et al. COVID-19 vaccines: current status and implication for use in Indonesia | Ophinni | Acta Medica Indonesiana; $2020 . \quad$ Available from: http://www.actamedindones.org/index.php/ijim/article/view /1648/0. [Last accessed on 05 May 2021]

24. Nugroho A. Pakar UGM: Miliki 65,3 persen efikasi vaksin sinovac tetap aman. Universitas Gadjah Mada; 2021. Available from: https://ugm.ac.id/id/berita/20607-miliki-65-3-persenefikasi-vaksin-sinovac-aman. [Last accessed on 05 May 2021]

25. Dharmaningtias DS. Demographic data on the implementation of covid-19 vaccination. Doemstical Political Divison, Info Singkat, A Brief Study of Actual and Strategic Issues; 2021. Available from: https://berkas.dpr.go.id/puslit/files/info_singkat/Info\%20Singkat -XIII-3-I-P3DI-Februari-2021-207-EN.pdf. [Last accessed on 08 May 2021] 